\title{
Evaluation of depressive symptoms in obese patients with or without acanthosis nigricans
}

\author{
Yueye Huang, ${ }^{* 1}$ Jiaqi Chen, ${ }^{* 1,2}$ Jie Yang, ${ }^{3}$ Kexiu Song, ${ }^{1}$ Xingchun Wang, ${ }^{1,2}$ \\ Xiaoyun Cheng, ${ }^{1}$ Shen $Q u^{1,2}$
}

\begin{abstract}
${ }^{1}$ Department of Endocrinology and Metabolism, Shanghai Tenth People's Hospital, Tongji University School of Medicine, Shanghai; ${ }^{2}$ Department of Clinical Medicine, Nanjing Medical University, Nanjing; ${ }^{3}$ Department of Thoracic Surgery, Shanghai Pulmonary Hospital, Tongji University School of Medicine, Shanghai; China
\end{abstract}

*These authors contributed equally to this work and should be considered as co-first authors.

\begin{abstract}
OBJECTIVE: Acanthosis nigricans (AN) has been closely associated with obesity. Depression has also been shown to be disproportionally prevalent among obese people. However, there is still a paucity of studies on the relationship between depressive symptoms and AN in obese patients. This study examined the difference in metabolic disorders and depressive symptoms between simple obesity and obesity-related AN. METHODS: A total of 88 obese patients treated in our department were selected for analysis. They were divided into simple obesity $(\mathrm{OB} \mathbf{n}=30)$ and obesity with acanthosis nigricans $(A N \mathrm{n}=58)$. A control $(\mathrm{CON})$ group included 56 normal weight healthy volunteers. The self-administrated Beck Depression Inventory-II questionnaire was used. General characteristics and clinical data were collected for analysis. RESULTS: The frequency of depressive symptoms was recorded as $67.2 \%$ in the $\mathrm{AN}$ group, $43.4 \%$ in the OB group, and $3.6 \%$ in the CON group $(\mathrm{P}<\mathbf{0 . 0 0 1})$. The severity of depression in the AN group was significantly higher than in the $\mathrm{OB}$ group and $\mathrm{CON}$ group $(\mathrm{P}<0.001)$. Patients with moderate depressive symptoms had higher levels of inflammatory markers than those with mild symptoms depression. Free fatty acid (FFA) and uric acid (UA) level in the AN group were significantly increased compared with the $O B$ group $(P=0.010, P=0.020)$. Discrimination was associated with depressive symptoms $(\mathrm{P}<0.001)$. CONCLUSION: Obese patients had a higher risk of depressive symptoms, which were even higher in patients with $A N$. AN is associated with more depressive symptoms and high inflammation status. Psychological intervention should be started early to prevent further physical and pathological impairment in obese patients, especially obese patients with $A N$.
\end{abstract}

Key words: Acanthosis Nigricans, Depressive symptoms, Obesity 


\section{INTRODUCTION}

It was estimated that obesity was responsible for approximately 365,000 preventable deaths in United States in 2000. .,2 Between 1980 and 2004, the prevalence of obesity doubled from $15 \%$ to $33 \%$ in adults and the prevalence of overweight tripled from 5.5\% to $17 \%$ in children. ${ }^{3}$ Projections based on the National Health and Nutrition Examination Surveys (NHANES) predict that if the current trends continue, more than half $(51.1 \%)$ of US adults are likely to be obese and $86.3 \%$ are likely to be overweight or obese by $2030 .{ }^{4}$

It was postulated that obese people suffer mentally and emotionally from their weight condition because of negative perception. ${ }^{5}$ Studies have shown that obese individuals are the last acceptable targets of discrimination. ${ }^{6,7}$

Acanthosis nigricans (AN) is common in obese patients and is characterized by hyperpigmented, usually brownish black papillomatous velvety thickening of the epidermis that primarily affects the axillae, posterior neck fold, flexor skin surfaces, umbilicus, and occasionally mucosal surfaces. ${ }^{8,9}$ The cause of AN has been reported to be hyperinsulinemia, which arises as a consequence of insulin resistance associated with obesity. ${ }^{8}$ Meanwhile, other studies have demonstrated an association of AN with hyperinsulinemia and type two diabetes mellitus (T2DM), and the recent increase of T2DM among children and youth has heightened interest in children's health, including screening children for AN as a risk factor for diabetes. ${ }^{8,9}$ Based on related studies, it is not surprising that $\mathrm{AN}$ has been strongly associated with metabolic abnormalities. ${ }^{10,11}$ But studies focusing on the relation between $\mathrm{AN}$ and depressive symptoms in obese patients are still lacking.

We sought to examine how AN affects the metabolism and depressive symptoms of obese patients. This research is based on a subsample of a perspective, randomized study. We hypothesize that obese patients with AN have a higher risk of metabolic abnormalities and depressive symptoms.

\section{PARTICIPANTS AND METHODS}

\section{Participants}

A total of 88 patients with obesity who had been treated in our department (Department of Endocrinology and Metabolism, Shanghai Tenth People's Hospital, Tongji University School of Medicine, Shanghai, China) were selected for participation in this study as well as 56 healthy volunteers aged from 17 to 32 years old. The participants were divided into three groups: obesity group $(\mathrm{n}=30$, BMI $>28 \mathrm{~kg} / \mathrm{m}^{2}$, no acanthosis nigricans, OB), obesity with acanthosis nigricans group $\left(\mathrm{n}=58, \mathrm{BMI}>28 \mathrm{~kg} / \mathrm{m}^{2}\right.$, with acanthosis nigricans, $\mathrm{AN}$ ), and normal control $(\mathrm{CON})$ group $\left(\mathrm{BMI}<25 \mathrm{~kg} / \mathrm{m}^{2}, \mathrm{n}=56\right.$, aged $>18$ years, CON). The study was approved by the Ethics Committee and the Clinical Registration Number is ChiCTR-OCS-12002381. Informed consent was obtained from each of the participants.

Inclusion criteria: Obesity was assessed according to the guidelines for prevention and control of overweight and obesity in Chinese adults. ${ }^{12}$ The following scale for AN was used..$^{13}$ Neck severity: 0 , Absent or not detectable on close inspection 1; 1, Present: clearly present on close visual inspection, not visible to the casual observer, extent not measurable; 2, Mild: limited to the base of the skull, does not extend to the lateral margins of the neck (usually $<3$ inches in breadth); 3 , Moderate: extending to the lateral margins of the neck (posterior border of the sternocleidomastoid, usually 3-6 inches), should not be visible when the participant is viewed from the front; 4, Severe: extending anteriorly ( $>6$ inches), visible when the participant is viewed from the front. Axilla severity: 0, Absent: not detectable on close inspection; 1, Present: clearly present on close visual inspection, not visible to the casual observer, extent not measurable; 2, Mild: localized to the central portion of the axilla, may have gone unnoticed by the participant; 3, Moderate: involving entire axillary fossa, but not visible when the arm is against the participant's side; 4, Severe: visible from front or back in the unclothed participant when the arm is against the participant's side. In this study, each subject enrolled with AN had a score greater than 2. All subjects had completed secondary or higher education.

\section{METHODS}

Height, weight, and waist circumference were directly measured by trained technicians and body mass 
index (BMI) was calculated as weight in kilograms divided by height in meters squared. Body fat percentage, visceral fat fraction, basal metabolic rate, and body age were measured with light clothes and without shoes by Omron HBF-358 (Q40102010L01322F, Japan). For all participants, morning fasting venous blood, serum specimens, total cholesterol, triglycerides, lowdensity lipoprotein cholesterol (LDL), high density lipoprotein cholesterol (HDL), free fatty acids, and uric acid were collected, and the blood glucose and insulin at $0 \mathrm{~min}, 30 \mathrm{~min}, 60 \mathrm{~min}, 120 \mathrm{~min}$, and $180 \mathrm{~min}$ were also measured after a $75 \mathrm{~g}$ oral glucose tolerance test (OGTT).

The homeostasis model of assessment for insulin resistance (HOMA-IR) was calculated on the basis of fasting values of plasma glucose and insulin according to the HOMA model formula: HOMA-IR = fasting insulin * fasting glucose, divided by $22.5 .{ }^{14}$ Significant insulin resistance was considered to be present when HOMA-IR was $>1.64 .{ }^{15}$

\section{Assessment of depressive symptoms}

The Beck Depression Inventory-II (BDI-II) was used in this study. ${ }^{16}$ The Chinese version of BDI-II is translated from the original version and has been widely used in China. ${ }^{17}$ The BDI-II measures symptoms of depression based on 21 items corresponding to physical function, mood, and cognitive functioning, each question offering four possible responses which are scored from zero to three. For each individual item, a score of 0 denotes "I am not depressed", while a score of 3 denotes "I am extremely depressed". Higher scores represent greater depressive symptoms. 0-13: indicates minimal depressive symptoms, 14-19: indicates mild depressive symptoms, 20-28: indicates moderate depressive symptoms, 29-63: indicates severe depressive symptoms.

Forty-seven (47) of the 54 participants with depressive symptoms were further analyzed for risk factors of depressive symptoms; the other 7 were not included because of the patients' refusal. Risk factors of depressive symptoms for analysis included sex, education, job, monthly average household income, quality of sleep, experience of discrimination and other negative life events. The Pittsburgh sleep quality index (PSQI) ${ }^{18}$ was used to measure the quality of sleep. The discrimination scale described by
Williams and Smith was used. ${ }^{19,20}$ Frequency ranging from "almost everyday" to "a few times a year" was defined as meaning "Yes", and "less than one a year" and "never" meant "No".

\section{STATISTICAL ANALYSIS}

Comparative analysis to identify differences was performed with the $\chi^{2}$ test or Fisher's exact test on categorical variables and Student's t test or the MannWhitney U test on continuous variables. The one-way ANOVA test was used to measure the difference among three groups. All statistical tests were two-sided, and a two-tailed $p$ value of less than 0.05 was considered statistically significant. All statistical analysis was performed with SPSS version 16.0 for Windows (SPSS Inc, Chicago, IL).

\section{RESULTS}

There were overall 54 individuals with at least mild depressive symptoms, 52 obese patients, and 2 volunteers. Among the 54 participants, 47 participants completed the analysis of risk factors for depressive symptoms and the result demonstrated that experience of discrimination due to obesity was associated with mild or greater depression symptoms in this cohort (Table 1). There was no significant difference in the experience of discrimination between the $\mathrm{AN}$ and OB groups $(\mathrm{P}=0.365)$.

Table 2 depicts the BDI-II score and depressive symptoms among different groups. The occurrence of depressive symptoms among the three groups was significantly different. Obese patients had higher BDI-II scores and a higher rate of depressive symptoms. AN patients had a higher BDI-II score and a higher rate of depression symptoms than the OB group $(\mathrm{P}<0.001)$. There were no severe depression symptoms in this series. In $\mathrm{AN}$, the rate of depressive symptoms was $67.2 \%$, significantly higher than that in $\mathrm{OB}, \mathrm{P}=0.040$, and the mean scores of the three groups were $14.4 \pm 4.9$, $11.8 \pm 5.9$ and $6.6 \pm 3.1$, respectively (Table 2 ).

Compared with the CON group, the neck circumference, waist circumference, hip circumference, waist-to-hip ratio, percentage of body fat, visceral fat fraction, basal metabolic rate, body age, and BMI were increased in the $\mathrm{AN}$ and $\mathrm{OB}$ groups $(\mathrm{OB}$ vs $\mathrm{CON}$ 
Table 1. Risk factors of depressive symptoms

\begin{tabular}{|c|c|c|c|}
\hline & No. & $\%$ & $P$ value \\
\hline Sex & & & 0.183 \\
\hline Male & 11 & 24.4 & \\
\hline Female & 36 & 36.4 & \\
\hline Education & & & 0.792 \\
\hline$<$ high school & 17 & 33.3 & \\
\hline high school & 17 & 35.4 & \\
\hline >high school & 13 & 28.9 & \\
\hline Stable job & & & 0.285 \\
\hline Yes & 23 & 37.7 & \\
\hline No & 24 & 28.9 & \\
\hline $\begin{array}{l}\text { Monthly average household } \\
\text { income }\end{array}$ & & & 0.555 \\
\hline Low & 18 & 28.1 & \\
\hline Medium & 17 & 37.8 & \\
\hline High & 12 & 34.3 & \\
\hline Quality of sleep & & & 0.722 \\
\hline Poor & 21 & 34.4 & \\
\hline Good & 26 & 31.3 & \\
\hline $\begin{array}{l}\text { Experience of discrimination } \\
\text { because of obesity }\end{array}$ & & & 0.000 \\
\hline Yes & 36 & 48.6 & \\
\hline No & 11 & 15.7 & \\
\hline $\begin{array}{l}\text { Experience of other negative life } \\
\text { events }\end{array}$ & & & 0.793 \\
\hline Yes & 7 & 36.8 & \\
\hline No & 40 & 32.0 & \\
\hline
\end{tabular}

$\mathrm{P}<0.001$, AN vs $\mathrm{CON} \mathrm{P}<0.001$ ), though there were no significant differences between the two groups. Blood test results showed OB and AN patients had increased serum levels of C-reactive protein (CRP) (OB vs $\mathrm{CON} \mathrm{P}=0.001$, AN vs $\mathrm{CON} \mathrm{P}<0.001$ ), total cholesterol (TC) (OB vs $\mathrm{CON} \mathrm{P}=0.002, \mathrm{AN}$ vs $\mathrm{CON}$ $\mathrm{P}<0.001$ ), triglyceride (TG), uric acid (UA), HOMAIR (OB vs CON $\mathrm{P}<0.001$, AN vs CON $\mathrm{P}<0.001$ ), and blood glucose at each time point compared with $\mathrm{CON}$ group (OB vs $\mathrm{CON} \mathrm{P}<0.001$, $\mathrm{AN}$ vs $\mathrm{CON} \mathrm{P}<0.001$ at $0,60,120 \mathrm{~min}, \mathrm{P}=0.021$ at $30 \mathrm{~min}$ and 0.016 at $180 \mathrm{~min})$. The OB group had decreased serum levels of thyroid stimulating hormone $(\mathrm{TSH})(\mathrm{P}=0.004)$ and increased plasma insulin concentrations at $0 \mathrm{~min}$ and 180 min $(\mathrm{P}<0.001)$ than the CON group. In addition, the AN group had higher levels of FFA $(\mathrm{P}=0.010)$, UA $(\mathrm{P}=0.020)$, and plasma insulin concentrations at $30 \mathrm{~min}$ and $60 \mathrm{~min}$ than $\mathrm{OB}(\mathrm{P}=0.011, \mathrm{P}=0.023)$ at each point than $\mathrm{CON}$ group $(\mathrm{P}<0.001)$ (Table 3$)$.

We also compared the biochemical parameters in patients with mild depressive symptoms $(n=43)$ and with moderate depressive symptoms $(n=11)$ : the two groups had significant differences in BMI $(\mathrm{P}=0.02)$, FFA $(\mathrm{P}=0.010)$, and UA $(\mathrm{P}=0.02)$, while CRP, TC, TG, FPG, TSH showed no significant difference (Table 4). Table 5 depicts the correlations between BMI, depression severity, insulin resistance (HOMA-IR), CRP, and severity of AN group. The results showed that AN group was associated with depression, BMI, and HOMA-IR (correlation index was $0.367,0.508$, and 0.445 , respectively) $(\mathrm{P}<0.001)$. In addition, depression was associated with $\mathrm{BMI}$ and HOMA-IR (correlation index was 0.345 and 0.306 , respectively) $(\mathrm{P}<0.001)$. BMI was associated with HOMA-IR and CRP (correlation index was 0.670 and 0.440 , respectively) $(\mathrm{P}<0.001)$. HOMA-IR was associated with CRP (correlation index was 0.406 ) $(\mathrm{P}<0.001)$.

Monthly average household income low: 800-1200

Table 2. Comparison of BDI-II scores and depressive symptomatology rates between the three groups

\begin{tabular}{lcccc}
\hline & $\mathbf{A N}$ & $\mathbf{O B}$ & $\mathbf{C O N}$ & P value \\
& $\mathbf{N = 5 8}$ & $\mathbf{N = 3 0}$ & $\mathbf{N = 5 6}$ & 0.000 \\
\hline Score & $14.4 \pm 4.9$ & $11.8 \pm 5.9$ & $6.6 \pm 3.1$ & $<0.001$ \\
Minimal depression & $19(32.8 \%)$ & $17(56.7 \%)$ & $54(96.4 \%)$ & $<0.001$ \\
Depression & $39(67.2 \%)$ & $13(43.3 \%)$ & $2(3.6 \%)$ & \\
Mild depression & $30(51.7 \%)$ & $11(36.7 \%)$ & $2(3.6 \%)$ & \\
Moderate depression & $9(15.5 \%)$ & $2(6.7 \%)$ & 0 & \\
Severe depression & 0 & 0 & 0 & \\
\hline
\end{tabular}

OB: obese without acanthosis nigricans; AN: obese group with acanthosis nigricans; CON: control. One-way ANOVA was used to identify the difference. 
Table 3. Comparison of patients' characteristics and blood test results

\begin{tabular}{|c|c|c|c|}
\hline & $\begin{array}{c}\text { OB } \\
\mathrm{N}=\mathbf{3 0}\end{array}$ & $\begin{array}{c}\mathrm{AN} \\
\mathrm{N}=\mathbf{5 8}\end{array}$ & $\begin{array}{l}\mathrm{CON} \\
\mathrm{N}=56\end{array}$ \\
\hline $\mathrm{M} / \mathrm{F}$ & 0.5 & 0.7 & 0.5 \\
\hline Age (year) & $25.9 \pm 8.3$ & $26.6 \pm 9.5$ & $24.4 \pm 7.6$ \\
\hline Height (cm) & $164.7 \pm 6.4$ & $166.4 \pm 8.2$ & $162.1 \pm 5.3$ \\
\hline Neck circumference $(\mathrm{cm})$ & $38.8 \pm 3.5^{b}$ & $38.3 \pm 5.3^{b}$ & $31.1 \pm 2.6$ \\
\hline Waist circumference $(\mathrm{cm})$ & $101.2 \pm 6.6^{\mathrm{b}}$ & $104.7 \pm 16.4^{b}$ & $71.2 \pm 6.0$ \\
\hline Hip circumference (cm) & $105.0 \pm 5.9^{\mathrm{b}}$ & $111.1 \pm 16.4^{b}$ & $92.1 \pm 3.0$ \\
\hline Waist/Hip ratio & $0.94 \pm 0.07^{\mathrm{b}}$ & $0.97 \pm 0.06^{\mathrm{b}}$ & $0.77 \pm 0.05$ \\
\hline Percentage of body fat $(\%)$ & $36.4 \pm 4.5^{b}$ & $36.2 \pm 4.2^{b}$ & $25.1 \pm 4.5$ \\
\hline Visceral fat fraction & $16.2 \pm 5.4^{\mathrm{b}}$ & $15.8 \pm 6.9^{b}$ & $3.6 \pm 3.6$ \\
\hline Basal metabolic rate (kcal) & $1725.6 \pm 188.5^{\mathrm{b}}$ & $1769.4 \pm 323.3^{\mathrm{b}}$ & $1249.0 \pm 160.2$ \\
\hline Body age (year) & $59.1 \pm 10.0^{\mathrm{b}}$ & $55.0 \pm 11.9^{\mathrm{b}}$ & $25.0 \pm 5.1$ \\
\hline BMI & $32.86 \pm 4.14^{\mathrm{b}}$ & $34.92 \pm 6.57^{b}$ & $21.14 \pm 1.97$ \\
\hline $\mathrm{FFA}(\mathrm{mmol} / \mathrm{l})$ & $0.58 \pm 0.18$ & $0.71 \pm 0.21^{\mathrm{a}, \mathrm{c}}$ & $0.540 \pm 0.21$ \\
\hline CRP (mg/l) & $4.33 \pm 2.97^{\mathrm{b}}$ & $10.71 \pm 30.4^{\mathrm{b}}$ & $0.394 \pm 0.35$ \\
\hline $\mathrm{UA}(\mathrm{umol} / \mathrm{l})$ & $377.59 \pm 71.19^{b}$ & $445.00 \pm 112.3^{\mathrm{b}, \mathrm{c}}$ & $268 \pm 67.70$ \\
\hline $\mathrm{TC}(\mathrm{mmol} / \mathrm{l})$ & $5.19 \pm 1.87^{\mathrm{b}}$ & $5.02 \pm 1.13^{b}$ & $4.19 \pm 0.80$ \\
\hline $\mathrm{TG}(\mathrm{mmol} / \mathrm{l})$ & $2.34 \pm 1.69^{\mathrm{b}}$ & $1.94 \pm 1.28^{\mathrm{b}}$ & $0.90 \pm 0.80$ \\
\hline TSH (mIU/l) & $1.96 \pm 1.19^{\mathrm{b}}$ & $2.68 \pm 1.25$ & $3.08 \pm 1.62$ \\
\hline \multicolumn{4}{|l|}{ Blood glucose $(\mathrm{mmol} / \mathrm{l})$} \\
\hline (OGTT:0 min) & $5.95 \pm 1.71^{\mathrm{b}}$ & $5.82 \pm 1.56^{\mathrm{b}}$ & $4.70 \pm 0.22$ \\
\hline (OGTT:30min) & $10.18 \pm 3.76^{b}$ & $9.41 \pm 2.36^{\mathrm{a}}$ & $7.69 \pm 1.02$ \\
\hline (OGTT:60min) & $11.74 \pm 4.74^{b}$ & $10.20 \pm 3.75^{b}$ & $6.14 \pm 1.37$ \\
\hline (OGTT:120min) & $10.06 \pm 6.07^{b}$ & $8.62 \pm 4.23^{b}$ & $4.81 \pm 0.81$ \\
\hline (OGTT:180min) & $7.18 \pm 5.26^{b}$ & $6.46 \pm 3.89^{\mathrm{a}}$ & $3.83 \pm 0.83$ \\
\hline \multicolumn{4}{|l|}{ Plasma insulin (mU/l) } \\
\hline (OGTT:0 min) & $23.84 \pm 11.84^{b}$ & $30.88 \pm 15.12^{b}$ & $9.68 \pm 3.33$ \\
\hline (OGTT:30min) & $78.52 \pm 47.43$ & $191.35 \pm 128.16^{\mathrm{b}, \mathrm{c}}$ & $107.29 \pm 46.16$ \\
\hline (OGTT:60min) & $113.56 \pm 68.52$ & $206.39 \pm 121.43^{\mathrm{b}, \mathrm{c}}$ & $84.92 \pm 61.67$ \\
\hline (OGTT:120min) & $131.50 \pm 103.06$ & $160.16 \pm 145.39^{b}$ & $57.93 \pm 35.21$ \\
\hline (OGTT:180min) & $65.01 \pm 46.05^{b}$ & $71.57 \pm 56.60^{b}$ & $17.68 \pm 21.99$ \\
\hline HOMA-IR & $6.23 \pm 3.28^{b}$ & $8.24 \pm 5.43^{\mathrm{b}}$ & $2.03 \pm 0.74$ \\
\hline
\end{tabular}

OB: obese without acanthosis nigricans; AN: obese group with acanthosis nigricans; CON: control; BMI: Body Mass Index; M/F: Male/Female; FFA: Free fatty acid; CRP: C reactive protein; UA: Uric Acid; TC: total cholesterol; TG: triglyceride; FPG: fast plasma glucose; TSH: Thyroid stimulating hormone; HOMA-IR: homeostasis model of assessment for insulin resistance. vs $\mathrm{CON}$, ${ }^{\mathrm{P}}<0.05$, ${ }^{\mathrm{b}} \mathrm{P}<0.01$; vs $\mathrm{OB},{ }^{\mathrm{c}} \mathrm{P}<0.05,{ }^{\mathrm{d}} \mathrm{P}<0.01$. Student's t test or Mann-Whitney $\mathrm{U}$ test were used to identify the difference.

yuan, medium: 1200-2000 yuan, high: >2000 yuan; the Pittsburgh sleep quality index (PSQI) ${ }^{18}$ was used to measure the quality of sleep: a score $>8$ indicates poor quality sleep, a score $<8$ indicates good quality sleep.
Discrimination, a measure of major experience of unfair treatment, included 9 items and their frequency; ${ }^{19,20}$ the frequency ranged from almost every day to a few times a year, signifying Yes, otherwise less than one 
Table 4. Comparison of biochemical parameters in participants with different degrees of depressive symptoms

\begin{tabular}{lccc}
\hline & $\begin{array}{c}\text { Mild } \\
\mathbf{N}=\mathbf{4 3}\end{array}$ & $\begin{array}{c}\text { Moderate } \\
\mathbf{N}=\mathbf{1 1}\end{array}$ & P value \\
\hline BMI & $33.6 \pm 3.1$ & $38.2 \pm 6.8$ & 0.020 \\
FFA & $0.6 \pm 0.2$ & $0.8 \pm 0.2$ & 0.010 \\
CRP & $4.5 \pm 2.4$ & $17.0 \pm 44.5$ & 0.655 \\
UA & $410.7 \pm 81.6$ & $491.7 \pm 123.5$ & 0.020 \\
TC & $5.0 \pm 1.4$ & $4.9 \pm 1.2$ & 0.993 \\
TG & $1.9 \pm 1.5$ & $1.7 \pm 0.7$ & 0.948 \\
FPG & $6.2 \pm 2.2$ & $6.9 \pm 4.0$ & 0.914 \\
TSH & $2.6 \pm 1.1$ & $2.5 \pm 1.5$ & 0.990 \\
\hline Compared
\end{tabular}

Compared with patients with mild depressive symptoms $(n=43)$, the patients with moderate depressive symptoms $(n=11)$ had a higher level of BMI, FFA, and UA. Mann-Whitney U test was used to identify the difference.

a year and never, signifying No. Experience of other negative life events was defined as experience of at least one negative life event, including divorce, the death of parents or spouse. The $\chi^{2}$ test was used to analyze the difference.

\section{DISCUSSION}

In recent years, China's rapid economic development has led to a sharp increase in caloric intake and in the proportion of individuals living a sedentary lifestyle. Obesity has therefore become a challenging health problem for adults as well as children. Obese patients suffer from discrimination and prejudice in all aspects of life from obviously unfair treatment in employment, education, etc. ${ }^{21}$ Discrimination is harmful to its victims in many ways and can have enduring effects. ${ }^{22}$ It has been reported that the social prejudice and discrimination experienced by obese individuals leads to chronic tension and anxiety, re- sulting in many negative effects. ${ }^{23}$ Other studies have reported that exposure to weight-related teasing and anti-fat attitudes among adolescents typically results in depression and decreased self-esteem. Obese preschoolers have higher levels of emotional distress and psychiatric problems, and obese adults have a higher incidence of depression. ${ }^{24-29}$ Our study confirmed that depressive symptoms were associated with the experience of discrimination.

The general incidence of depression is under $5 \%$. The rates of depression among obese individuals are about 1.5 to 2 times those of individuals of normal weight. ${ }^{30-32}$ Our study showed a high proportion of depressive symptoms in obese patients, which increased with the appearance of AN. The obese patients in the present study required treatment from a medical professional and therefore may suffer more than those who did not seek medical care.

Interestingly, in our study the discrimination experienced by individuals in the AN group and $\mathrm{OB}$ group did not exhibit a significant difference, which indicated that there were other factors that may bring about depressive symptoms. Studies have shown that higher levels of pro-inflammatory cytokines are found in depressed patients ${ }^{33}$ and that those cytokines can induce somatic symptoms common in depression, such as fatigue and appetite disturbances, which in turn contribute to obesity. ${ }^{34}$ In our study significant differences were observed in the levels of FFA, UA, and plasma insulin concentrations between $\mathrm{AN}$ and $\mathrm{OB}$. Moreover, when we compared biochemical parameters between mild depression and moderate depression, there was a significant difference in terms of BMI, FFA, and UA $(\mathrm{P}<0.05)$. These results indicate that a higher risk of depressive symptoms in AN may be associated with worse metabolic dysfunction. In addi-

Table 5. Correlation of different variables $(n=144)$

\begin{tabular}{lccccc}
\hline & AN symptoms & Depression & BMI & HOMA-IR & CRP \\
\hline AN symptoms & 1 & $0.367^{*}$ & $0.508^{*}$ & $0.445^{*}$ & 0.080 \\
Depression & $0.367^{*}$ & 1 & $0.345^{*}$ & $0.306^{*}$ & -0.011 \\
BMI & $0.508^{*}$ & $0.345^{*}$ & 1 & $0.670^{*}$ & $0.440^{*}$ \\
HOMA-IR & $0.445^{*}$ & $0.306^{*}$ & $0.670^{*}$ & 1 & $0.406^{*}$ \\
CRP & 0.080 & -0.011 & $0.440^{*}$ & $0.406^{*}$ & 1 \\
\hline
\end{tabular}

$* \mathrm{P}<0.01$, correlation is significant at the 0.01 level (2-tailed). AN symptoms measured by a score mentioned previously; score ranged from 2 to 4. 
tion, AN symptoms were closely associated with BMI. However, whether there is causality between depressive symptoms and metabolic disorders or whether the effect is bidirectional still needs to be investigated.

Epidemiological studies have demonstrated that the incidence of AN in the general population is $7 \%$, while it is present in up to $74 \%$ of obese people, with obesity being recognized as the most common etiological factor. ${ }^{35}$ Furthermore, studies have demonstrated that AN is linked to insulin resistance. ${ }^{36,37}$ In obesity, $\mathrm{AN}$ is a physical marker of insulin resistance and of more profound metabolic alterations. Indeed, AN is frequently associated with the metabolic syndrome. ${ }^{38,39}$ The importance of our finding is that physicians should be aware of the existence of depressive symptoms which may be more severe if $\mathrm{AN}$ is also present and may exist in combination with more severe metabolic dysfunction and difficulty in losing weight. Psychological intervention should be recommended as one of the treatment methods to support and improve the lives of these patients.

There are several limitations in this study. First of all, the number of patients in this study is relatively small and larger studies are needed to confirm these results. Secondly, a selection bias may exist as this population represented only those obese patients who had the motivation to seek medical care.

In conclusion, the risk of having depressive symptoms is high in obese patients who require intervention. Discrimination is associated with depressive symptoms in obese patients. Compared with $\mathrm{OB}, \mathrm{AN}$ is associated with more severe metabolic disorders and more depressive symptoms. Surveillance of depressive symptoms is recommended in obese patients, while psychological intervention is also recommended in this group of patients.

\section{COMPETING INTERESTS}

The authors declare that they have no conflict of interest.

\section{ACKNOWLEDGEMENTS}

This research was supported by a Shanghai CDC Grant (SHDC12012303) and CSE Grant 13020260411.
We sincerely thank Aaron Gusdon for editing the language of this manuscript.

\section{REFERENCE}

1. Mokdad AH, Marks JS, Stroup DF, Gerberding JL, 2004 Actual causes of death in the United States, 2000. JAMA 291: 1238-1245.

2. Mokdad AH, Marks JS, Stroup DF, Gerberding JL, 2005 Correction: actual causes of death in the United States, 2000. JAMA 293: 293-294.

3. Ogden CL, Yanovski SZ, Carroll MD, Flegal KM, 2007 The epidemiology of obesity. Gastroenterology 132: 2087-2102.

4. Wang Y, Beydoun MA, Liang L, Caballero B, Kumanyika SK, 2008 Will all Americans become overweight or obese? estimating the progression and cost of the US obesity epidemic. Obesity (Silver Spring) 16: 2323-2330.

5. Warschburger P, 2005 The unhappy obese child. Int J Obes (Lond) 29: Suppl 2: 127-129.

6. Falkner NH, French SA, Jeffery RW, Neumark-Sztainer D, Sherwood NE, Morton N, 1999 Mistreatment due to weight: prevalence and sources of perceived mistreatment in women and men. Obes Res 7: 572-576.

7. Stunkard AJ, Sorensen TI, 1993 Obesity and socioeconomic status--a complex relation. N Engl J Med 329: 1036-1037.

8. Jones LH, Ficca M, 2007 Is Acanthosis Nigricans a reliable indicator for risk of type 2 diabetes? J Sch Nurs 23: 247-251.

9. Sinha S, Schwartz RA, 2007 Juvenile acanthosis nigricans. J Am Acad Dermatol 57: 502-508.

10. Brickman WJ HJ, Silverman BL, Metzger BE, 2010 Acanthosis nigricans identifies youth at high risk for metabolic abnormalities. J Pediatr 156: 87-92.

11. Ice CL, Murphy E, Minor VE, Neal WA, 2009 Metabolic syndrome in fifth grade children with acanthosis nigricans: results from the CARDIAC project. World J Pediatr 5: 23-30.

12. Chen C, Lu FC, 2004 The guidelines for prevention and control of overweight and obesity in Chinese adults. Biomed Environ Sci 17: Suppl: 1-36.

13. Burke JP, Hale DE, Hazuda HP, et al, 1999 A quantitative scale of acanthosis nigricans. Diabetes Care 22: 1655-1659.

14. Bonora E, Targher G, Alberiche M, et al, 2000 Homeostasis model assessment closely mirrors the glucose clamp technique in the assessment of insulin sensitivity: studies in subjects with various degrees of glucose tolerance and insulin sensitivity. Diabetes Care 23: 57-63.

15. Chitturi S, Abeygunasekera S, Farrell GC, et al, 2002 NASH and insulin resistance: Insulin hypersecretion and specific association with the insulin resistance syndrome. Hepatology 35: 373-379.

16. Beck AT, Steer RA, Brown GK, 1996 Manual for the 
Beck Depression Inventory-II. San Antonio: TX: Psychological Corporation.

17. Wang ZYC, Huang J, 2011 Reliability and validity of the Chinese version of Beck Depression Inventory-II among depression patients. Chinese Ment Health J 25: 476-480.

18. Buysse DJ, Reynolds CF, Monk TH, Berman SR, Kupfer DJ, 1989 The Pittsburgh Sleep Quality Index: a new instrument for psychiatric practice and research. Psychiatry Res 28: 193-213.

19. Williams DR, Yu Y, Jackson JS, Anderson NB, 1997 Racial differences in physical and mental health: socioeconomic status, stress, and discrimination. J Health Psychol 2: 335-351.

20. Krieger N, Smith K, Naishadham D, Hartman C, Barbeau EM, 2005 Experiences of discrimination: validity and reliability of a self-report measure for population health research on racism and health. Soc Sci Med 61: 1576-1596.

21. Puhl R, Brownell KD, 2001 Bias, discrimination, and obesity. Obes Res 9: 788-805.

22. Kessler RC, Mickelson KD, Williams DR, 1999 The prevalence, distribution, and mental health correlates of perceived discrimination in the United States. J Health Soc Behav 40: 208-230.

23. Dalrymple KL, Galione J, Hrabosky J, et al, 2011 Diagnosing social anxiety disorder in the presence of obesity: implications for a proposed change in DSM-5. Depress Anxiety 28: 377-382.

24. Simon GE, Ludman EJ, Linde JA, 2008 Association between obesity and depression in middle-aged women. General hospital psychiatry 30: 32-39.

25. Roberts RE, Kaplan GA, Shema SJ, Strawbridge WJ, 2000 Are the obese at greater risk for depression? Am J Epidemiol 152: 163-170.

26. Patten SB, Williams JV, Lavorato DH, Khaled S, Bulloch AG, 2011 Weight gain in relation to major depression and antidepressant medication use. J Affect Disord 134: 288-293.

27. Vila G, Zipper E, Dabbas M, et al, 2004 Mental disorders in obese children and adolescents. Psychosom Med 66: 387-394.

28. Wardle J, Cooke L, 2005 The impact of obesity on psychological well-being. Best Pract Res Clin Endocrinol
Metab 19: 421-440.

29. Davison KK, Birch LL, 2002 Processes linking weight status and self-concept among girls from ages 5 to 7 years. Dev Psychol 38: 735-748.

30. Strine TW, Mokdad AH, Dube S, Ret al, 2008 The association of depression and anxiety with obesity and unhealthy behaviors among community-dwelling US adults. Gen Hosp Psychiatry 30: 127-137.

31. Gadalla TM, 2009 Association of obesity with mood and anxiety disorders in the adult general population. Chronic Dis Can 30: 29-36.

32. Preacher KJ, Hayes AF, 2008 Asymptotic and resampling strategies for assessing and comparing indirect effects in multiple mediator models. Behav Res Methods 40: 879-891.

33. Lyngdoh T, Bochud M, Glaus J, et al, 2013 Associations of serum uric acid and SLC2A9 variant with depressive and anxiety disorders: a population-based study. PloS one 8: e76336.

34. Schiepers OJ, Wichers MC, Maes M, 2005 Cytokines and major depression. Prog Neuropsychopharmacol Biol Psychiatry 29: 201-217.

35. Dassanayake AS, Kasturiratne A, Niriella MA, et al, 2011 Prevalence of Acanthosis Nigricans in an urban population in Sri Lanka and its utility to detect metabolic syndrome. BMC Res Notes 4: 25.

36. Atwa M, Emara A, Balata M, et al, 2013 Serum leptin, adiponectin, and resistin among adult patients with acanthosis nigricans: correlations with insulin resistance and risk factors for cardiovascular disease. Int J Dermatol 53: e410-420.

37. Sadeghian G, Ziaie H, Amini M, Ali Nilfroushzadeh M, 2009 Evaluation of insulin resistance in obese women with and without acanthosis nigricans. J Dermatol 36: 209-212.

38. Nguyen TT, Keil MF, Russell DL, et al, 2001 Relation of acanthosis nigricans to hyperinsulinemia and insulin sensitivity in overweight African American and white children. J Ped 138: 474-480.

39. Kobaissi HA, Weigensberg MJ, Ball GD, Cruz ML, Shaibi GQ, Goran MI, 2004 Relation between acanthosis nigricans and insulin sensitivity in overweight Hispanic children at risk for type 2 diabetes. Diabetes care 27: 1412-1416. 